\title{
Dandy-Walker malformation-postaxial polydactyly syndrome
}

INSERM

\section{Source}

INSERM. (1999). Orphanet: an online rare disease and orphan drug data base. DandyWalker malformation-postaxial polydactyly syndrome. ORPHA:1566

Dandy-Walker malformation with postaxial polydactyly syndrome is a syndromic disorder with, as a major feature, the association between Dandy-Walker malformation and postaxial polydactyly. The Dandy-Walker malformation has a variable expression and is characterized by a posterior fossa cyst communicating with the fourth ventricle, the partial or complete absence of the cerebellar vermis, and facultative hydrocephalus. Postaxial polydactyly includes tetramelic postaxial polydactyly of hands and feet with possible enlargement of the fifth metacarpal and metatarsal bones, as well as bifid fifth metacarpals. 